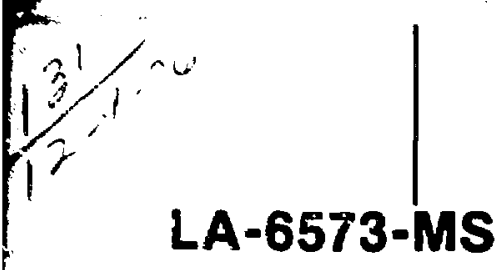

Informal Report

UC-34

Issued: November 1976

\title{
A Generalized Chisquare Kinematic Fitting Procedure Applicable to Multiwire Proportional Chambers
}

by

E. A. Wadinger *

"University of Virginia, Charlottesvilie, VA 22903

s scientifie laboratory

of the University of California

IOS ALAMOS. NEW MEXICO 87545

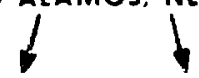

An Alfirmative Action/Equal Opportunity Employer 
Printed in the United States of Amcrica. Aratishle from National Technical Informat:on Servict

U.S. Department of Commerce

5285 Port Royal Road

Sprngfield VA 2216

Price: Printed Copy \$3.50 Microfictic $\$ 3.00$

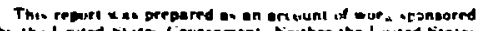

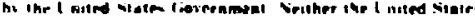

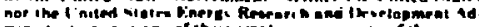

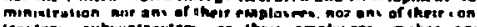

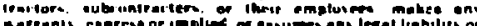

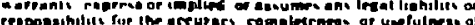

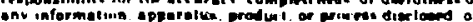

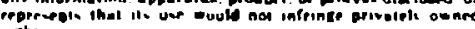
righis 


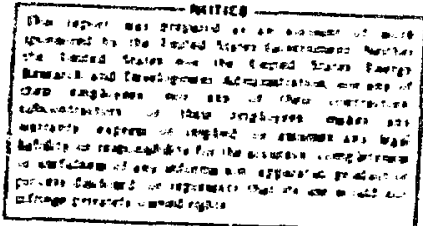

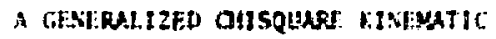

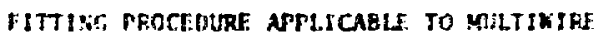

PROFORTICNAL GUMAES

by

1. A. Madiinger

\section{Mestract}

A chisquture fiting procedure is presented which allowg iypothesis to be fil direcely to measured parametern. The hypo. thesis is oxhibited through a series of constraire cquations which aly consain rariables with no measured colnterpert. Thas this ecthol is a perteraidication of previous procedures.

\section{ISTRODKTIOA}

This report presents a general method of analying data by perfoxaing a chisquare ( $\left.x^{2}\right)$ fis to the data using kincmatic paraecters. This nethod is nore applicable to counter experikents thar: older versions. I The data are analyzed phrough a series of constraint equotions. Thus, for cxanple. if onc were measuring ip elastic scatering, one vould "fit" a set of hineatic yariables which obey the rip hincmatics to a set of Eeasured quantitics. The degree of agreement between the weasured and fited sets of variables is given by a nuber "chisquare" defined in the next section. One needs only a single paraweter, $x^{2}$, to deteraine whether of not an evenr is acceptable, where hopefully the maximus aeceptable chtsquare is determined unanbiguous ly.

The previous methods suffer by the requizement that a set of variables appearing in all the constraint equations must have "measured" counterparts. 2,3 For bubble chamber experinents, this is a perfectly adequnte method, but for counter or chamber experiments, where one neasures points in space sather than hinceatic variables, certats adjustacnts sust be ato. One requent ly terltes kinewalic wariables froe the seasured poines i sometiacs difficult procedure), thes decs the intareir fieting. The sssuption is alse pencrally eade that the derived "ecasured" values ate not correlated. i.c. the crrop axtis is diagotial (see the next section). This approxteation is set accurate for enty experitenzs.

In this pefert a femeralization of the prew tats fieting procedure is introdused which alions a hape. thesis to be fit directiy to measured parancicts (points in space. et:.) These direce eessurezenss are the least likely to have correlations so that it is sore appropriate to use a diagosal crror wtrix. Also. the necessity of doing interwediate cajculations is eliainated. So if one cere acsuring elastic ip scatecting wizh a tro-aze speceroacer. one could fie kinealtic variables obeying the sp kinewatics directly to the acasured points in space. The fit is perfored using the constraint equations defining the relationship between the aessured set of values and the kncatic variables. the constraint equations defining the kineatics.

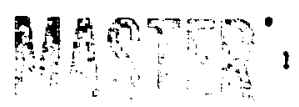




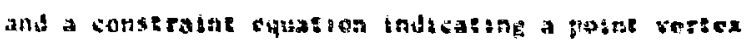

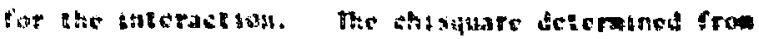

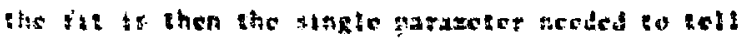

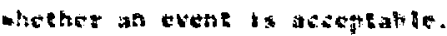

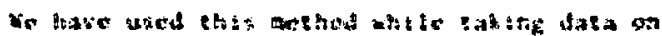

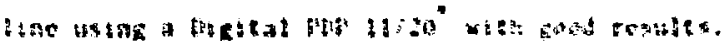

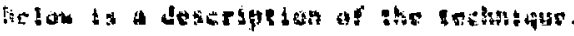

11. mones

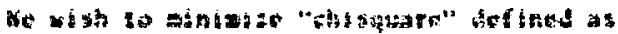

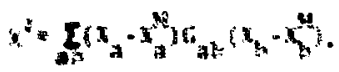

mere

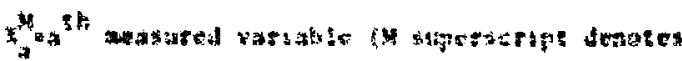
susasuretury.

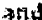

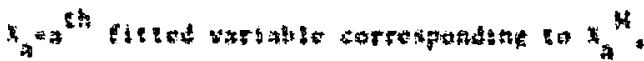

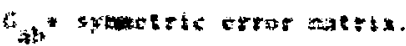

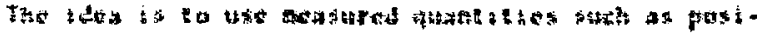

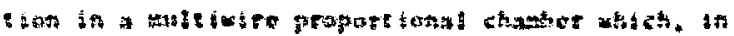

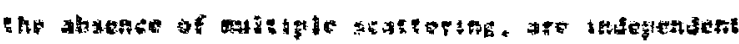

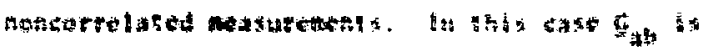
Is a

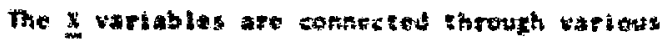

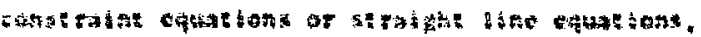

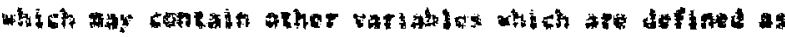

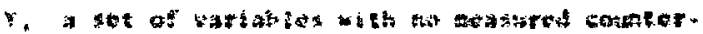

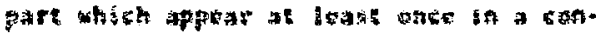

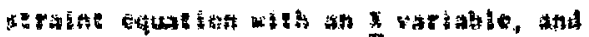

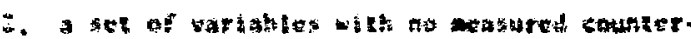

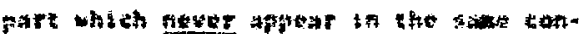

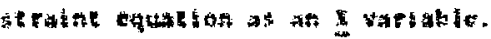

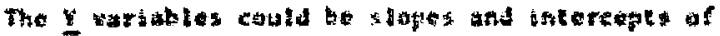

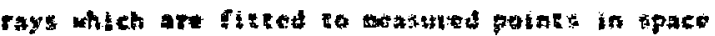

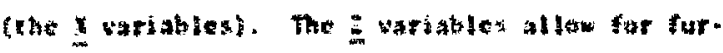

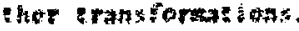

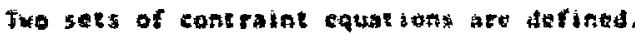

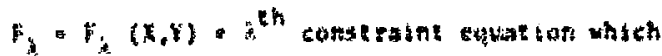
is a funceitury of $x$ and I inty with at lexsh onte watale in cach rutatien.

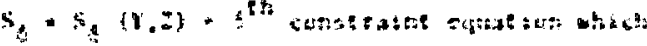

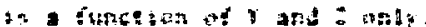

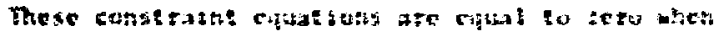

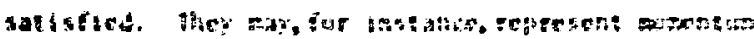
ard energy candertalisis.

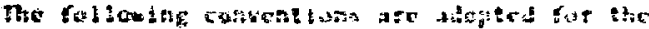

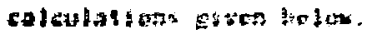

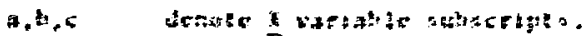

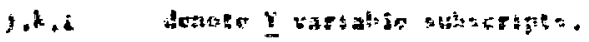

$$
\begin{aligned}
& 5, x+4 \text { denite }
\end{aligned}
$$

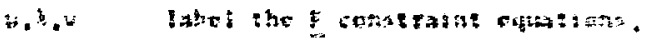

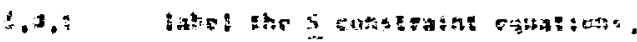

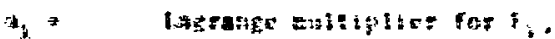

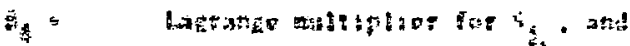

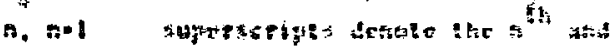

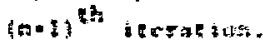

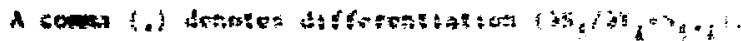

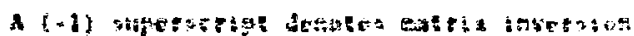

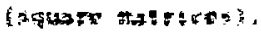

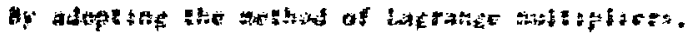

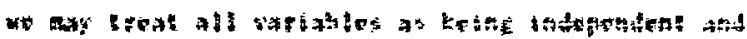

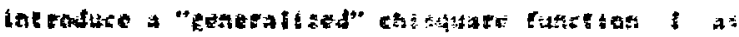

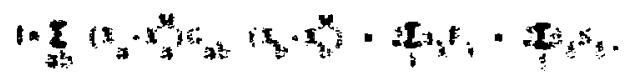

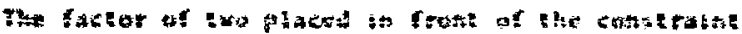

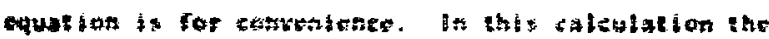

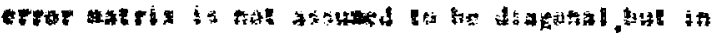

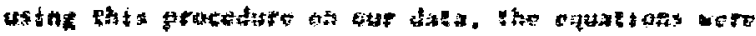

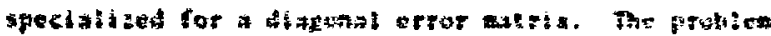

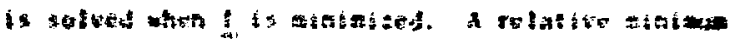

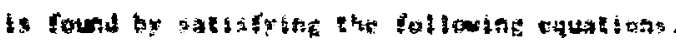

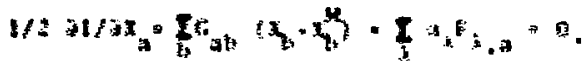

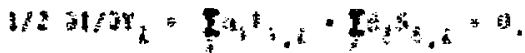

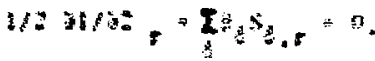

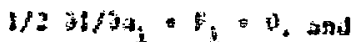

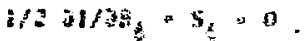

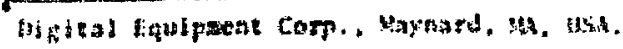


Suce ltese equations are peneraldy diffisule o. is. passthie to solve sxactly, an zersetve procedure is aised. fiven $x^{n}, r^{n}, z^{n}, a^{n}, E^{n}$ after the $n^{\text {th }}$ iters. isan. deterxino $x^{n+1}, x^{n+1}, 2^{n+1}, a^{n-1}, e^{n+1}$ for the inci) th iteration. This is done by expanding the $F$, ard 5 bonstraine cquations 'o first order is a Taylor icrtex. Givan the folloxing ses of equatlons.

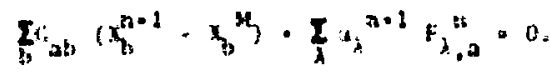

$$
\begin{aligned}
& F_{i}^{n+1} F_{n, k}^{n} \cdot \sum_{i} k^{n+1} s_{4, i}^{n}=0 \\
& \sum_{0}^{n+1} s_{5,8}^{n} \cdots
\end{aligned}
$$

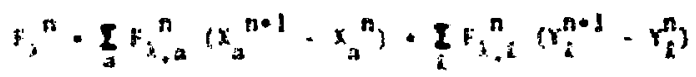

$$
\begin{aligned}
& \text { * 1. and }
\end{aligned}
$$

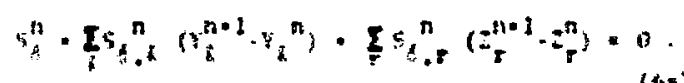

tinte that

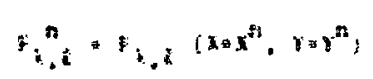

axt

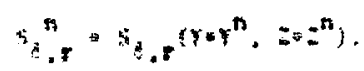

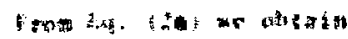

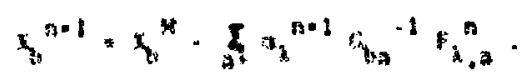

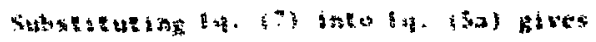

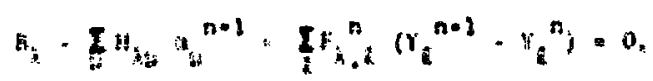

where

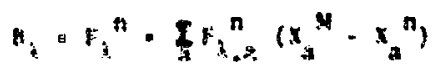

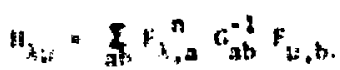

solve for nel tros tiy. (s).

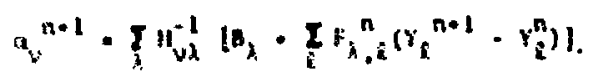

If theze are no $Y$ variables. the problex is solved since

$$
u^{n-1} \cdot \sum_{i} H_{i j}^{-1} B_{i}
$$

This is the solution used by previous firting prosedures.

Continuing by substseuting fạ. (11) into Eq. I30j (3a). defining

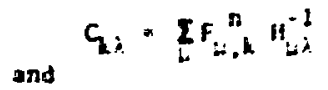

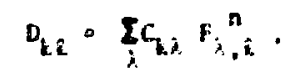

and solving for $Y_{j}^{n+1}$ we obtain

$$
y_{j}^{n+2} \cdot r_{j}^{n} \cdot \sum_{i k}^{n} v_{j k}^{-1} C_{k} b_{i} \cdot \sum_{k} e_{j}^{n+1} v_{j k}^{-1} s_{j, k}^{n}
$$

(If there are no s-type constrsine equations, the probjee is solved.) befining

$$
\begin{aligned}
& x_{j}=-\sum_{i k j}^{-j} c_{k i} B_{i} \\
& R_{j k}=\sum_{k} a_{j k}^{-1} s_{i k}^{n} . \\
& u_{b_{2}}=\sum_{i} s_{b i} a_{20} \text {. and } \\
& t_{t}=s_{t}^{n} \cdot \sum_{z} s_{t a}^{n} n_{i} \text {. }
\end{aligned}
$$

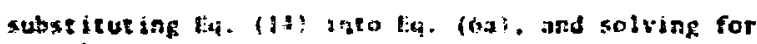
nel fives

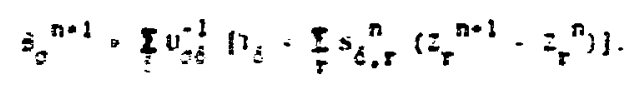

(The problew is solved if there are no $\Xi$ variables.) tefine

$$
\begin{aligned}
& 0_{2} \cdot \mathrm{Iu}_{\mathrm{s}}^{-1} \mathrm{~T}_{\mathrm{i}} \\
& P_{\text {er }} \cdot t_{z}^{-1} s_{\varepsilon, r}^{n} \\
& Q^{28} \cdot \sum_{0.5}^{n} s_{e r} \text { and } \\
& v_{s}=\sum_{s, s}^{n} 0_{s}
\end{aligned}
$$


Substitute Eq. (19) into kq. (4a) and solve for $z_{t}^{n+1}$.

$$
z_{t}^{n+1}=z_{t}^{n}-\sum_{s} Q_{t s}^{-1} v_{s}
$$

For the first iteration $(n=1)$, the $\underline{x}$ variables may be initialized with their measured values, the $\underline{I}$ and $I$ variables with values corresponding to the "expected" result. The fit is complete when $x^{2}$ reaches a minime and the constraint equations are sitisfied to within an acceptable tolerance.

\section{EXAMLE}

is an example to illustrate the method, consider the two body elastic scattering process $\pi p m p$. The apparatus is illustrated in Fig. 1. The scattered pion is detected in a spectrometer consisting of two sets of MPCs (multivire proportional dianbers) before the magnet and two sets after. The recoil proton is detected by two sets of MrPCs. We also assume that the incident pion trajectory and aosentum are known to within errors determined by the phase space.

We have the following set of peasured variables: the points in space $\left(X_{1}, Y_{1}, \ldots, X_{6}, Y_{6}\right)$ deterained from the MPCs and the incident pion variables $\left(P_{0}, \theta_{0}, D_{0}\right)$. The errors in the position weasurements are deternined by the MaPC resolution and multiple scattering. The errors in che incident pion paraneters are deterained by the bean channel phase space acceptance. These measured variables constitute the $x$-type variables defined in the previous section.

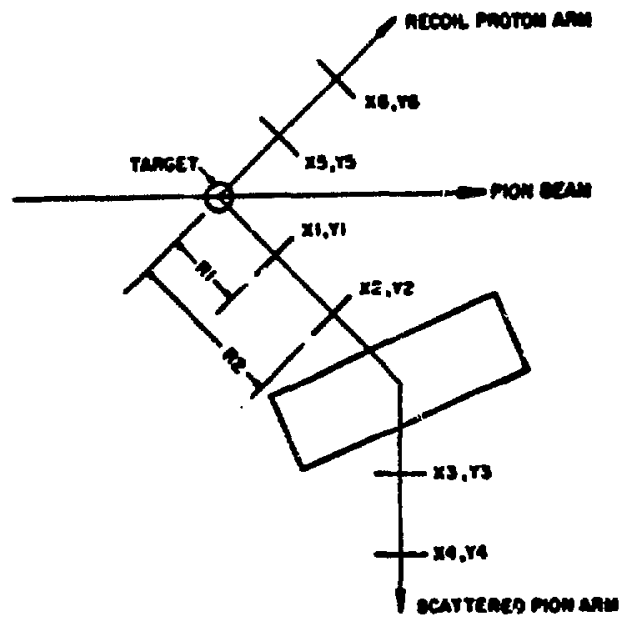

An acceptable event wust satisfy the hinewatic constraint equations for the $n p$ scattering. These equations require the scattered pion variables $\left(\theta_{\pi}, \phi_{\pi}, p_{n}\right)$ and the recoil proton variables $\left(\theta_{p}\right.$. $\left.p_{p}, p_{p}\right)$. The va iables $\left(x_{v}, r_{v}, z_{v}\right)$ which define the position of the vertex are also needed. These derived variables appear below in the same constraint equations as the measured parameters and thus meet the criterion for $\underline{Y}$-type variables.

The constraint equations are 1 isted below he define the functions $A$ to illustrate the variable dependence rather than explicitly writing the equations. The constants $R_{1}$ to $R_{6}$ are the known positions of the chambers. Constraint equitions $F_{2}$ to $F_{12}$ relate the measured points in space to the kinematic parameters and vertex position. Equations $F_{13}, F_{14}$, and $F_{15}$ require momentum conservation and $F_{16}$ requires energy conservation.

$$
\begin{aligned}
& F_{1}=X_{1}-A_{2}\left(\theta_{\pi}, \theta_{\pi}, X_{v}, Y_{v}, Z_{v}, R_{1}\right), \\
& F_{2}=r_{1}-A_{2}\left(\theta_{\pi}, \theta_{\pi}, x_{v}, Y_{v}, z_{v}, R_{1}\right), \\
& F_{3}=X_{2}-A_{1}\left(\theta_{\pi}, \theta_{\pi}, X_{v}, Y_{v}, Z_{v}, R_{2}\right), \\
& F_{4}=\gamma_{z}-A_{2}\left(\theta_{\pi}, \theta_{\pi}, X_{v}, Y_{v}, Z_{v}, R_{2}\right), \\
& F_{3}=X_{3}-A_{3}\left(\theta_{\pi}, \theta_{\pi}, P_{3}, X_{v}, Y_{v}, Z_{v}, R_{3}\right) \text {, } \\
& F_{6}=Y_{3}-A_{4}\left(\theta_{\pi}, \hat{\theta}_{\pi}, F_{\pi}, X_{v}, Y_{v}, Z_{v}, R_{3}\right), \\
& F_{7}=X_{6}-A_{3}\left(\theta_{\pi}, \theta_{\pi}, P_{\pi}, X_{v}, Y_{v}, Z_{v}, R_{4}\right), \\
& F_{0}=Y_{4}-A_{4}\left(F_{\pi}, \theta_{\pi}, P_{\pi}, X_{v}, Y_{v}, Z_{v}, R_{b}\right) \text {. } \\
& F_{s}=X_{s}-A_{s}\left(\theta_{p}, \theta_{p}, X_{v}, Y_{v}, Z_{v}, R_{s}\right) \text {, } \\
& F_{10}=Y_{5}-A_{6}\left(\theta_{p}, \theta_{p}, X_{v}, Y_{v}, Z_{v}, R_{5}\right) \text {, } \\
& F_{11}=X_{c}-A_{s}\left(\theta_{p}, \theta_{p}, X_{v}, Y_{v}, Z_{v}, R_{G}\right), \\
& F_{12}=Y_{6}-A_{G}\left(\theta_{p}, \theta_{p}, X_{v}, Y_{v}, Z_{v}, R_{6}\right) \text {. } \\
& F_{13}=F_{13},\left(P_{0}, e_{0}, \theta_{0}, P_{\pi}, e_{\pi}, \Phi_{\pi}, P_{p}, \theta_{p}, \theta_{p}\right), \\
& F_{14}=F_{14}\left(P_{0}, \theta_{0}, \theta_{0}, P_{\pi}, \theta_{\pi}, \phi_{\pi}, P_{p}, \theta_{p}, \theta_{p}\right), \\
& F_{15}=F_{15}\left(P_{0}, \theta_{0}, \theta_{0}, P_{\pi}, \theta_{\pi}, \Phi_{\pi}, P_{p}, \theta_{p}, F_{p}\right. \text {, ano } \\
& F_{16}=F_{16}\left(E_{0}, E_{\pi}, E_{p}\right) \text {. }
\end{aligned}
$$

All of the above equations are $F$ type. If the beam paraneters were nonmeasured, $F_{1}, 2_{0} F_{16}$ would contain no measured $\underline{X}$-type variables and would then be $\underline{s}$ type constraint equations. ( $\left.P_{0}, \theta_{0}, \vartheta_{0}\right)$ appear only in these equations and would be $Z$ type variables.

Fig. 1 Geometry for $x^{2}$ fitting example. 


\section{I1. CONCLUSION}

This iterative procedure has been used and shown to converge. We have successfully used this cechnique to analyze two different experiments; one, a two-arm experiment to measure elastic $\pi^{2} \|$ scat tering and the other, a single arm experiment to look at elastic $\pi^{3} H$ and $\pi^{3}$ lle scattering. ${ }^{5}$ The $S$ type constraint equations and $z$-type variables were not necessary for this aralysis and were therefore eliminated in the computer program. This resulted in a gain in speed and efficiency in the computer routines. We found that three iterations were generally sufficient to give an adequate fit. HORThat computer programs for the above fitting procedure exist and listings may be obtained from the aut hor.

\section{ACKNOH IJ:DGMENTS}

I wish to thank the following people: Paul Glodis and Ben Nefkens of the University of California at Los Angeles for bringing to my attestion the chisquare fitting technique, James McCarthy of the University of Virginis for a critical reading of the mancript, and Ralph $C$. Minehart of the University of Virginia for useful suggestions in the use of the technique.

\section{REFERENCES}

1. SQUAN, Lawrence Radiation Laboratory Group A Programing Note ko. P-126 (July 1968).

2. Frank T. Solmitz, Ann. Rey. Nucl. Sci. 14, 375 (1964).

3. J. P. Berge, F. T. Solmitz, and H. D. Taft, fer. Sci. Instr. 32, 538 (1961).

4. R. Cole. J. MeCarthy, R. C. Minehart, and E. A. hadlinger, to be published.

5. J. McCarthy, R. C. Minehart, D. L. Roeder, E. A. hadlinger, H. Brandle, P. Clodis,

R. Haddock, B. Nefkens, J. Pratt, 0 . Sander, R. Sherman, F. Shively, and J. Spencer. to be published. 